\title{
Design and Fabrication of Energy Harvester using VIVACE (Vortex Induced Vibrations Aquatic Clean Energy)
}

\author{
Ashok B C, Akshay B L, Akshatha H, Akash D L, Bharath Yogendra
}

\begin{abstract}
Massive industrialization and population growth have led to a surge in the global demand for energy in recent years. Electricity is the new currency and developing countries are in desperate need of insatiable units of electricity. There is so much potential in Hydropower which when harnessed efficiently can show a phenomenal way in addressing the energy crisis. The conventional methods of harnessing the hydropower like generating electricity by damming, etc. have many limitations concerning environmental concerns, aquatic ecological imbalance and other issues. The paper is on Vortex Induced Vibrations Aquatic Clean Energy (VIVACE). It focuses on Clean Energy, making use of Vortex Induced Vibrations (VIV) to generate electricity. This paper describes the design and fabrication process related to energy harvester to harness VIVACE. CFD simulations done to obtain the feasible values of some important parameters involved in VIVACE are also discussed.
\end{abstract}

Keywords: Hydropower, Vortex shedding ,Vortex Induced Vibrations (VIV), Vortex Induced Vibrations Aquatic Clean Energy (VIVACE), Energy Harvester, CFD simulations.

\section{INTRODUCTION}

India, being a Growth engine, plays a crucial role in the world energy trends. There has been a unremitting growth in the electricity production in India from Financial Year (FY) 2010 to 2018(figure 1). 1201.5 billion units (BU) of electricity has been produced in FY 2018 in India ${ }^{[1]}$. The focus of Government of India has shifted to clean energy after it ratified the Paris Agreement ${ }^{[2]}$. The government is all set for boosting investment in renewable energy. In an annual

ranking of top 40 renewable energy markets conducted by EY, a UK accountancy firm, Indian renewable energy sector is the second most attractive renewable energy market in the world.According to India Brand Equity Foundation (IBEF), India looks to meet its energy demand on its own, which is

Revised Version Manuscript Received on August 19, 2019

Ashok B C, Visvesvaraya Technological University Department of Mechanical Engineering Vidyavardhaka College of Engineering, Mysuru, Karnataka, India.(email: bcashok@vvce.ac.in)

Akshay B L,, Assistant Professor, School of Bio-Engineering, Dept. of Genetic Engineering, Bharath Institute of Higher Education and Research, Chennai, Tamil Nadu, India. (email: akshayb1001@gmail.com)

Akshatha H, Student, School of Bio-Engineering, Dept. of Genetic Engineering, Bharath Institute of Higher Education and Research, Chennai, Tamil Nadu, India. (email: akshuakshatha0@gmail.com)

Akash D L, Student, School of Bio-Engineering, Dept. of Genetic Engineering, Bharath Institute of Higher Education and Research, Chennai, Tamil Nadu, India. (email: akashdlbenakanahalli@gmail.com)

Bharath Yogendra, Student, School of Bio-Engineering, Dept. of Genetic Engineering, Bharath Institute of Higher Education and Research, Chennai, Tamil Nadu, India. (email: yogibharath106@gmail.com) expected to reach 15,820 TWh (Terawatt hour) by 2040 . So renewable energy is set to play an important role.

The ramifications of conventional hydropower generation due to damming of water, change in flow of water, construction of roads and setting up of power lines are disastrous to aquatic ecosystem. How can engineers develop an energy harvester without unbalancing the aquatic ecosystem? Billions of units of power incessantly flow down rivers and streams, or wash up on shores, just to dissipate. It is also immensely challenging to harness: How can engineers tap this vast, restless resource to create sustainable energy that emulate fossil fuels and is compatible with existing power grids?.

The answer to above three questions is Vortex Induced Vibrations Aquatic Clean Energy (VIVACE). Energy crisis can be mitigated by utilizing the unused flow energy of water and producing electricity even in small scales. Using the principle of VIVACE, we can produce clean and renewable energy. During this era of depleting energy, we can obtain considerable amount of electricity. By incorporating VIVACE, areas having flowing water like streams, rivulets, rivers, etc. can extract energy and generate electricity.

This paper focuses on design and fabrication of energy harvester using VIV, familiarization with the concept of flow around the cylindrical structure and understanding the vibration phenomena of the cylindrical structure. Lift force $\mathrm{v} / \mathrm{s}$ flow time simulation in transient flow is done using CFD.

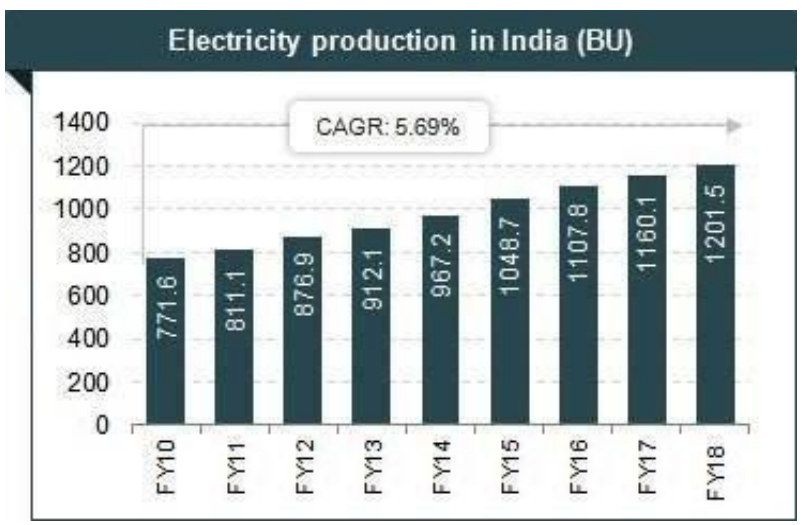

Figure 1: Electricity Production in India in each Financial Year (FY) from 2010 to 2018. ${ }^{[3]}$ 


\section{DESIGN METHODOLOGY}

- $\quad$ Background study

- Principle

- Principle parts

- $\quad$ Working Principle

The design of our Project goes as follows:

\section{A. Background study}

\section{Regime of flow}

One of the non-dimensionless numbers that is utilized to illustrate the flow around a smooth circular cylinder is the Reynolds number (Re). The Reynolds number is the ratio of the inertia forces to viscous forces. Flow regimes are obtained as the consequence of immense changes of the Reynolds number. The changes of the Reynolds number necessitate separation flows in the wake region of the cylinder, which are called vortices. Separation does not occur at meagre values of $\operatorname{Re}(\operatorname{Re}<5)$. When the $\operatorname{Re}$ is further increased, the separation starts to occur, becomes unstable, and initiates the phenomenon called vortex shedding at certain frequency. ${ }^{[4]}$

\section{Vortex Shedding}

The phenomenon of Vortex shedding (Fig 2.1) occurs when pairs of stable vortices are susceptible to small disturbances and become unstable at Re greater than 40 . For these values of $\mathrm{Re}$, the boundary layer over the cylinder surface will separate due to the pressure gradient forced by the divergent profile of the flow territory at the backside of the cylinder. Vortex shedding manifests at a particular frequency called as vortex shedding frequency $\left(f_{V}\right)$. This frequency normalized with the flow velocity

(U) and the cylinder diameter (D), can be seen as a function of the Reynolds number ${ }^{[4]}$. Moreover, the normalized vortex-shedding frequency is called Strouhal number (St).The relationship between $\mathrm{Re}$ in $\mathrm{X}$ - axis and $\mathrm{St}$ in $\mathrm{y}$-axis is seen in Figure 2.2.

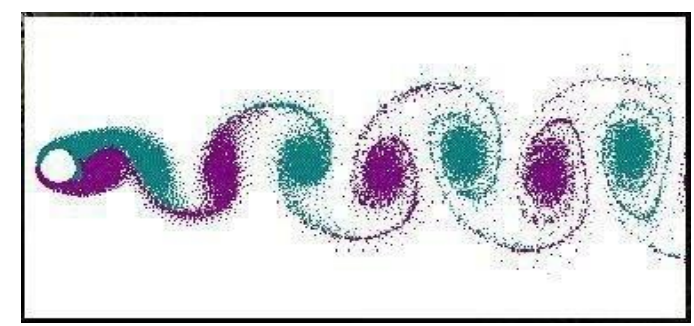

FIGURE 2.1: VORTEX SHEDDING

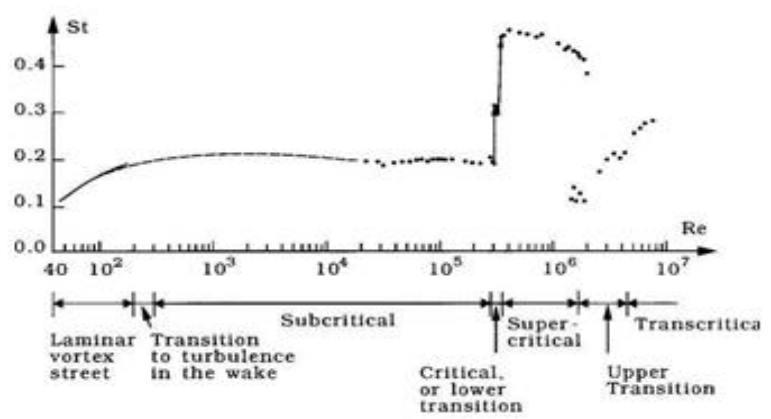

Figure 2.2: Graph of Reynolds number v/s Strouhal number for smooth circular cylinder

\section{Drag and Lift Forces}

The pressure distribution of the cylinder due to the flow will change periodically due to cyclical change of the vortex shedding, as a result generating a cyclical variation in the force components on the cylinder. Cross- flow and in-line directions are the force components. The lift force $\left(\mathrm{F}_{\mathrm{L}}\right)$ is in the cross-flow direction and the drag force $\left(F_{D}\right)$ is in the inline direction. The lift force develops when the vortex shedding begins and it varies at the vortex shedding frequency. Correspondingly, the drag force also has the oscillating part due to the vortex shedding, additionally as a result of friction and pressure difference, it also has a small force; this part is called the mean drag ${ }^{[5]}$.

\section{Cross-Flow and In-Line Vibrations of Cylindrical Structure}

Vibrations of bluff body materialise as the result of cyclical variations in the force components due to the vortex shedding. The vibrations can be divided as cross flow vibrations (Fig.2.3(a)) and in-line vibrations (Fig.2.3(b))). The lift force causes the cross-flow vibration while the drag force causes the in-line. Both vibrations are often called the vortex- induced vibrations

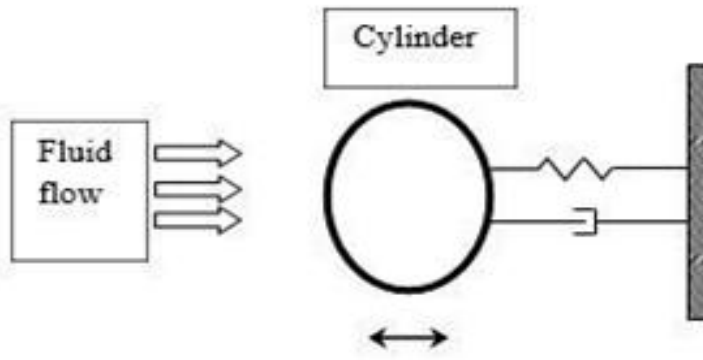

Inline vibration

Figure 2.3(a): Sketch of Inline Vortex Induced Vibrations ${ }^{[7]}$

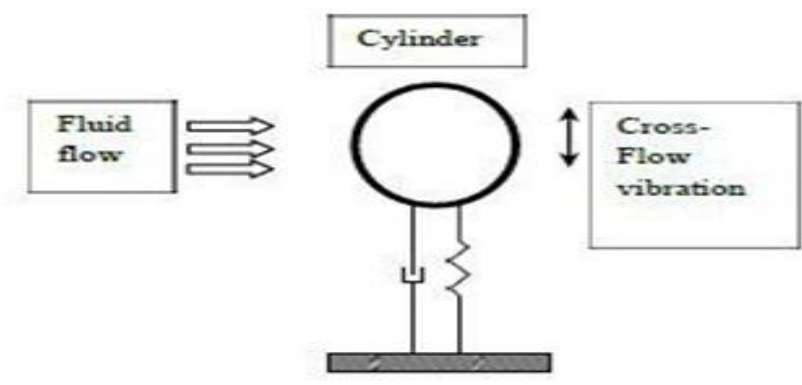

Figure 2.3(b): Sketch of Cross-Flow Vortex Induced Vibrations ${ }^{[7]}$ 


\section{5. $\quad$ Vortex Induced Vibrations (VIV)}

VIV result from vortices forming and shedding on the downstream side of a bluff body in a current. Vortex shedding alternates from one side to the other, thereby creating an oscillation / a vibration. The VIV phenomenon is non-linear. This property of VIV has huge implication as it can produce beneficial energy at high efficiency over a wide range of current speeds.

\section{Lock-in Frequency}

The vortex shedding frequency $\left(f_{\mathrm{V}}\right)$ will be trailing the stationary-cylinder Strouhal frequency (f) till the reduced velocity $(\mathrm{Vr})$ arrives at some value. When the flow speed increases, vortex shedding frequency $\left(f_{v}\right)$ does not follow the Strouhal frequency (f) and begins to follow the natural frequency $\left(f_{n}\right)$ of the system. This phenomenon takes place at a range. In this range, the vortex shedding frequency is locked into the natural frequency of the system. This phenomenon is known as the "lock-in" phenomenon. At this range, $f_{v}, f_{n}$ and $f$ have the same values, therefore, the lift force oscillates with the cylinder motion resulting in large vibration amplitudes.

\section{B.Principle:}

Vortex Induced Vibrations Aquatic Clean Energy (VIVACE)

Vortex Induced Vibration Aquatic Clean Energy (VIVACE) replicates the features of fish movements. Fish curve their bodies to glide between the vortices shed by their bodies in front of them. Their muscle power alone cannot propel them forward through the water at the speed they go, so they ride in each other's wake. ${ }^{[6][8]}$

Vortex induced vibrations are undulations that a rounded or cylinder-shaped object make in a flow of fluid, which can be air or water. The presence of the object puts twirls in the current's speed as it glides by. This causes eddies or vortices which generate a pattern on either sides of the object. The vortices push and pull the object up and down or left and right, perpendicular to the current. VIVACE works due to the presence of the bluff body in the current causing alternating vortices to form above and below the body. The vortices push and pull the passive body up and down creating mechanical energy i.e. vibrational energy. Later, this energy is converted into electricity. Because the oscillations of VIVACE would be slow, it is theorized that the system would not harm marine life like dams and water turbines can. ${ }^{[9][10]}$
C. Principle Parts
a. Bluff Body (Cylinder)
b. Rack
c. Pinion
d. Gear
e. Gear Coupled with DC generator
D. Working Principle

The Figure Below Shows the Working Principle of Our Project.

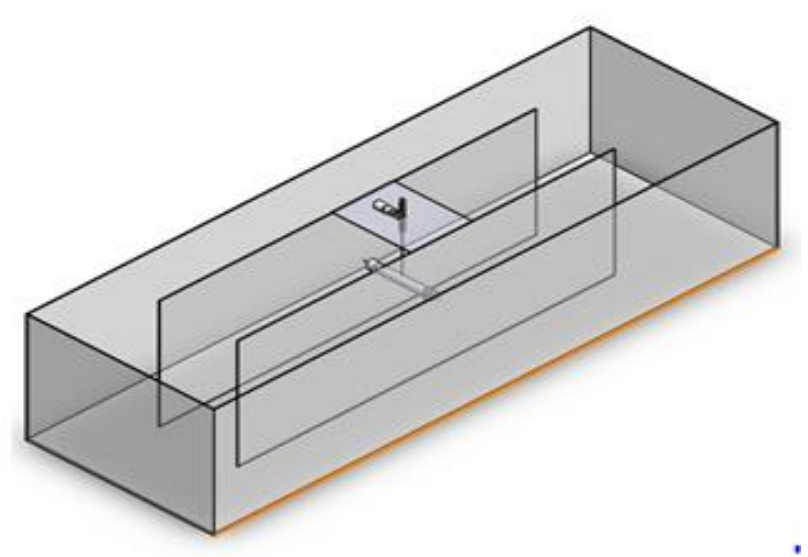

FIGURE 2.4: CAD MODEL OF EXPERIMENTAL SET-UP

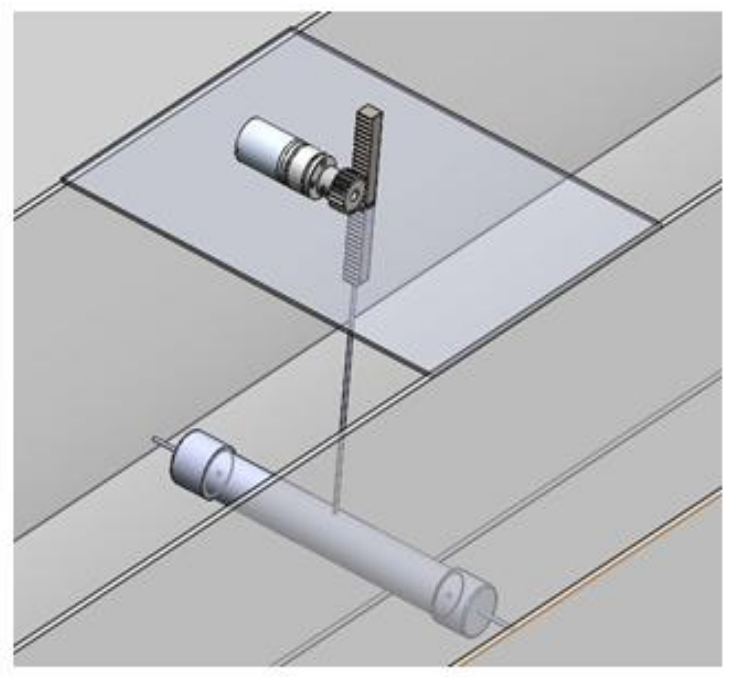

Figure 2.5: Enlarged view of gear coupled with Generator

The main principle behind this project is the conversion of linear oscillation of cylinder to rotational motion of the pinion. As the cylinder (Bluff body) is subjected to hydro-energy, it tends to oscillate due to the vortices formed around the structure of the cylinder, which can be converted to rotational energy to generate electricity. In this configuration, the cylinder is fixed axially and cross flow Vortex Induced Vibrations takes place. A rack and pinion arrangement is used for converting linear motion to rotational motion. As the cylinder reciprocates, the rack's movement rotates the pinion attached to it. The pinion drives the shaft which in turn rotates the alternator to generate power. Thus, electrical energy is obtained by continuous oscillation of the cylinder and DC output voltage is obtained.

\section{DESIGN SPECIFICATIONS}

\section{A. Formulae}

\section{Reynolds number}

One of the non-dimensionless hydrodynamic numbers that is used to describe the flow around a smooth circular cylinder is the Reynolds number $(\mathrm{Re})$. By the definition, 
the Reynolds number is the ratio of the inertia forces to viscous forces and formulated as:

$$
R_{e}=D U / v
$$

in which $D$ is the diameter of the cylinder, $U$ is the flow velocity and $v$ is the kinematic of the fluid.

\section{Vortex shedding}

Vortex shedding occurs at a certain frequency, which is called as vortex shedding frequency $\left(f_{v}\right)$. This frequency normalized with the flow velocity $U$ and the cylinder diameter $D$, can be seen as a function of the Reynolds number:

$$
f v=S_{t} U / D
$$

Furthermore, the normalized vortex- shedding frequency is called Strouhal number $(\mathrm{St})$ and the empirical formulae is:

$$
S_{\mathrm{t}}=0.198\left(1-\frac{19.7}{R_{\varepsilon}}\right)
$$

\section{Lift Force}

Lift force is formulated as follows:

$=\hat{E} \sin \left(\omega S t+\emptyset_{S}\right) . \hat{E}$ is the amplitude of the oscillation lift. The Vortex Shedding is represented by

$\omega_{s}=2 \pi / f_{v}$

and $\emptyset_{S}$ is the phase angle between oscillating force and vortex shedding. $\mathrm{C}_{\mathrm{L}}$ are the dimensionless parameters for lift force and can be calculated using

$$
\hat{E}=0.5 \times \rho_{\text {fluid }} L D U^{2} \times C_{L}
$$

where L, D and $\mathrm{U}$ are the cylinder length, cylinder diameter and flow velocity respectively. ${ }^{[12]}$

\section{Apparent mass}

$$
\begin{gathered}
\mathrm{m}_{\text {spp }}=m+\mathrm{m} \\
m_{p \text { dpo }}=\left(\rho_{\text {cyl }} \times L\right)+m_{\text {add }} \\
\mathrm{m}_{\text {dis }}=\rho_{\text {fluid }} \times V o l \\
\text { Vol }=\frac{\pi}{4}\left(D^{2} \times L\right)
\end{gathered}
$$

Where Vol is Volume of the cylinder, $m_{\text {dis }}$ is mass of fluid displaced by the cylinder, $\rho$ fluid is water density, mass $m_{\text {add }}$ represents additional mass added to the pipe, which will initially be set as 0 . The pipe mass $m_{\text {pipe }}$ was determined

\begin{tabular}{|c|c|c|}
\hline Property & Parameter & Values \\
\hline Cylinder material & M & PVC \\
\hline Cylinder Diameter & D & $25.4 \mathrm{~mm}$ \\
\hline Cylinder Length & $\mathrm{L}$ & $200 \mathrm{~mm}$ \\
\hline Water density & $\rho_{\text {fluid }}$ & $998 \mathrm{~kg} / \mathrm{m}^{3}$ \\
\hline $\begin{array}{c}\text { Linear cylinder } \\
\text { density }\end{array}$ & $\rho_{c y l}$ & $0.64 \mathrm{~kg} / \mathrm{m}$ \\
\hline Fluid temperature & $\mathrm{T}$ & $25^{\circ} \mathrm{C}$ \\
\hline $\begin{array}{c}\text { Water Kinematic } \\
\text { Density }\end{array}$ & $v$ & $\begin{array}{c}0.89 e^{-6} \\
\mathrm{~m}^{2} / \mathrm{s}\end{array}$ \\
\hline $\begin{array}{l}\text { Maximum Flow } \\
\text { speed }\end{array}$ & $\mathrm{U}$ & $1 \mathrm{~m} / \mathrm{s}$ \\
\hline
\end{tabular}
based on unit length density of $0.64 \mathrm{~kg} / \mathrm{m}$.

\section{Spring Stiffness}

Stiffness is a measure of the resistance offered by an elastic body to deformation. Spring stiffness $(\mathrm{k})$ is the force required to cause unit deflection. It is given by:

$$
k=\left(2 \pi f_{v}\right)^{2} \times \text { mapp }
$$

Where $f_{v}$ is vortex shedding frequency and mapp is apparent mass.

\section{ANALYTICAL CALCULATIONS:}

These are the known values:

Calculations:

Reynolds Number (Re):

$$
\begin{aligned}
& R=D U /=25.4 \times 10^{-3} \times 1 / \\
& \text { e } v \quad 0.89 e^{-6} \\
& R_{e}=28539.32 \\
& \underset{e}{R}=D U /=25.4 \times 10^{-3} \times 1 / \\
& 0.89 e^{-6} \\
& R_{e}=28539.32
\end{aligned}
$$

1.Strouhal Number $\left(S_{t}\right)$ :

$$
\begin{aligned}
& S_{\mathrm{t}}=0.198\left(1-\frac{{ }^{17 \prime}}{R_{e}}\right)=0.198\left(1-\frac{{ }^{17 . \prime}}{28539.32}\right. \\
& S_{t}=0.1978
\end{aligned}
$$

2. Vortex Shedding Frequency ( $f v)$ :

$$
f=S_{t} U_{/}=0.1978 \times 1,
$$

$$
\begin{aligned}
& f_{v}=7.787 \mathrm{~Hz} \\
& \text { 3.Lift force }(\square 1) \text { : } \\
& \begin{aligned}
& \hat{E}=0.5 \times \rho_{\text {fluid }} L D U^{2} \times C_{L} \\
&= 0.5 \times 998 \times 200 e^{-3} \times 25.4 e^{-3} \times 1^{2} \times 0.8 \\
&= 2.027 \mathrm{~N}
\end{aligned}
\end{aligned}
$$

Coefficient of lift $C_{L}$ is assumed 0.8 as a conservative estimate based on background research. Realistically, $C_{L}$ varies with displacement of the cylinder, so this value is an average 
Apparent mass (mapp):

$\mathrm{Vol}=\pi\left(D^{2} \times L\right)$

4

$={ }^{\pi}\left(\left(25.4 \times 10^{-3}\right)^{2} \times\left(200 \times 10^{-3}\right)\right)$

4

$=1.0134$

$\times 10^{-4} \mathrm{~m}^{3}$

$\mathrm{m}_{\text {dis }}=\rho_{\text {fluid }} \times$ Vol $=998 \times 1.0134 \times 10^{-4}$

$=0.10114 \mathrm{~kg}$

$m_{a d d}=0 \mathrm{~kg}$

$m_{\text {pipe }}=\left(\rho_{c y l} \times L\right)+m_{\text {add }}$

$m_{\text {pipe }}=\left(0.64 \times 200 \times 10^{-3}\right)+0$

$=0.128 \mathrm{~kg}$

$\mathrm{m}_{\mathrm{app}}=m_{\text {pipe }}+\mathrm{m}_{\mathrm{dis}}=0.22914 \mathrm{~kg}$

6. Spring Stiffness $(k)$ :

$\mathrm{k}=\left(2 \pi f_{v}\right)^{2} \times \operatorname{mapp}=(2 \times \pi \times 7.787)^{2} \times 0.22914$

$=548.53 \mathrm{~kg} / \mathrm{m}=548.53 \times 9.81 \mathrm{k}=5381.09 \mathrm{~N} / \mathrm{m}$

\section{CFD SIMULATION \& RESULTS}

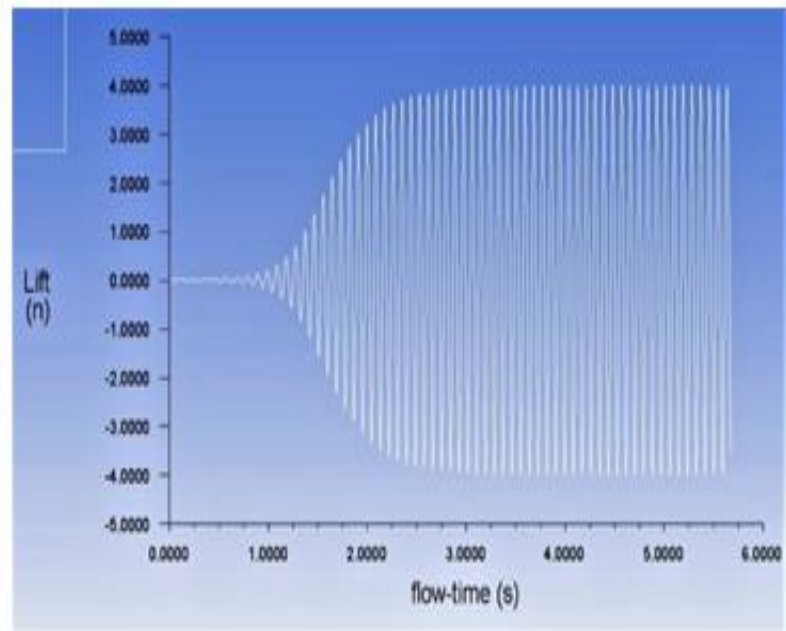

Figure 4.1 : CFD Simulation of Lift v/s Flow-time

The turbulent analysis is used in the CFD simulation as the Reynolds number is in turbulent region. K-omega (due to transient flow) type of turbulence model is chosen. In Figure 4.1 , the displacement history of the freely vibrating cylinder at $\operatorname{Re}=100$ is shown. The simulation is conducted for 6 second flow time. The vertical axis indicate the lift force in Newton and the horizontal axis is the flow duration in second. From the figure, it can be seen that the cylinder response rises after a second. Between the time value of 1 second to 2.5 seconds, the lift force is constantly rising. After 2.5 seconds, the lift force is constant and measures around $4 \mathrm{~N}$.

\section{CONCLUSION}

In this paper the VIV experiment on the energy harvesting device with a cylinder, rack and pinion and generator was done. Through mathematical calculations, CFD modelling and small-scale experiments, the potential for vortex-induced vibrations as an energy source was studied. Initial research was conducted on VIV theory and existing aquatic energy technologies, including VIVACE. Based on the background research, mathematical calculations were done in order to predict the relationship between experimental parameters and cylinder response. Based on the mathematical calculations, CFD modelling was done to obtain few key parameters involved to establish feasibility of small scale VIV testing and to create estimates for experimental results.

Overall, this project demonstrated the power generation at small scale. The output DC Voltage obtained lights up the LED in our case. Therefore, there is a potential for vortex-induced vibrations as a source of energy generation.

\section{SCOPE FOR FUTURE WORK}

The tests were conducted at low velocity. These speeds are significantly lower than those found in ocean currents and river flow. Increasing the Reynolds number by increasing fluid velocity and increasing cylinder diameter by a few inches would allow for results that could more accurately predict the potential for the technology under realistic conditions. Because of the low velocity for the fluid in the experiment, the lift force of the fluid acting on the cylinders was also small. This lift force could only overcome small amounts of damping and so damping was limited to the damping caused by the fluid. The vibrations of the cylinders subjected to fluid flow can only perform useful work if a system exists to extract the energy For large scale, where flow speeds are significantly high, piezoelectric material can be used for mast. As load increases on mast, stress will be induced in piezoelectric material thereby producing electricity more efficiently. AC generators can be used in case of high flow speeds. At low flow speeds, AC generators are not feasible as some energy generated will be wasted for the conversion of direct current to alternating current. But when velocity increases, load on mast also increases and use of AC generator is feasible.

\section{ACKNOWLEDGMENT}

The authors wish to acknowledge the Management of Vidyavardhaka College of Engineering (VVCE) for their consistent encouragement and support for the research activities. The authors are grateful for the support and guidance given by Dr. B Sadashive Gowda, Principal, VVCE, Dr. G.B Krishnappa, Dean of Research and Development, VVCE and Dr. G.V Naveen Prakash, Head of Mechanical Engineering Department, VVCE

\section{REFERENCES}

1. "International Energy Outlook 2017", A Energy Information Administration (EIA), Department of Energy, USA.

2. "Renewables 2017”, International Energy Agency (IEA).

3. "BP Statistical Review", Ministry of Power, Aranca Research.

4. Raghavan K et.al "Effect of Reynolds Number on Vortex Induced Vibrations", Proceedings of IUTAM Symposium, Hamburg, Germany, July 2007.

5. Lee J.H et.al "Integrated Power Take Off and Virtual Oscillator System for the VIVACE Converter: Vck System Identification", Proceedings of the 2009 ASME International Engineering Congress and Exposition, Paper \#, IMECE 2009-11430, Lake Buena Vista, FL, Nov. 13-19, 2009. 
6. Foulhoux L et.al "Forces and Moments on a Small Body Moving in a 3-D Unsteady Flow", Journal of Offshore Mechanics and Arctic Engineering (1993).

7. Kai L et.al "Two Tandem Cylinders with PassiveTurbulence Control in FIV: Relation of Oscillation Patterns to Frequency Response", Proceedings of the 36th OMAE 2017 Conf., Paper \#62131, Trondheim, Norway, June 25-30, 2017

8. Bernitsas M.M et.al "VIVACE (Vortex Induced Vibration Aquatic Clean Energy): A New Concept in Generation of Clean and Renewable Energy from Fluid Flow", OMAE 2006.

9. Bernitsas M.M et.al "The VIVACE Converter: Model Tests at High Damping and Reynolds Numbers Around 105", OMAE 2006.

10. Raghavan K et.al "Effect of Bottom Boundary on VIV for Energy Harnessing at $8 \times 103<\mathrm{Re}<1.5 \times 105$ ", OMAE 2007.

11. John D. Anderson Jr., "Computational Fluid Dynamics: The Basic With Applications", International Edition 1995, ISBN 0-07-113210-4.

12. B. Mutlu Sumer et.al "Hydrodynamics Around Cylindrical Structures: Advanced Series Of Ocean Engineering- Volume 26 (Revised Edition)", ISBN 981270-039-0. 